\title{
TAFONOMÍA DEL YACIMIENTO DE VERTEBRADOS PLEISTOCENOS DE CÚLLAR DE BAZA-1 (GRANADA, ESPAÑA)
}

\author{
M. Ángeles ALONSO DIAGO', Manuel HOYOS GÓMEZ'† \\ y $M$. Teresa ALBERDI \\ 1 Departamento de Geología. Museo Nacional de Ciencias Naturales, CSIC, José Gutiérrez \\ Abascal 2. 28006-Madrid. \\ 2 Departamento de Paleobiología, Museo Nacional de Ciencias Naturales, CSIC. José Gutiérrez \\ Abascal 2, 28006-Madrid. e-mail: alberdi@mncn.csic.es \\ $\doteqdot$ Recientemente fallecido
}

Alonso Diago, M.Á., Hoyos Gómez, M. y Alberdi, M.T. 2001. Tafonomía del yacimiento de vertebrados pleistocenos de Cúllar de Baza-1 (Granada, España). [Taphonomy of the Cúllar de Baza-1 Pleistocene vertebrate site (Granada, Spain).] Revista Española de Paleontología, 16(2), 283-298. ISSN 0213-6937.

\begin{abstract}
Analysis of the sedimentological characteristics of the Cúllar de Baza site, as much as several bone remain measurements have allowed us to interpretate the paleogeography and taphonomy of this site. Three successive bone accumulations have been found in the studied fossiliferous layers. Relevant differences regarding age and fauna associations have not been found among these accumulations. The apparition of three fossiliferous layers is due mainly to sedimentological processes. The fossiliferal sediments were formed in a paludine-lacustrine marginal environment, principally during low level water periods with paludine conditions, whereas during high water periods with carbonate precipitation the sediments are practically sterile. The bone association was formed mainly by predators-scavengers activities and the concentration of live fauna close to the paludine-lacustrine area. Signs of alluvio-fluvial streams contributing to the bone concentrations have not been found and the bone remains do not show abrasion marks. The site is an autochthonous bone accumulation with a rapid burial. For each bone recovered several variables were measured, the data obtained underwent graphic and statistical treatment that provided useful information for the site taphonomic interpretation.
\end{abstract}

Keywords: Taphonomy, Vertebrates, palustrine and lacustrine sedimentation, Middle Pleistocene, Granada.

\section{RESUMEN}

El análisis de las características sedimentológicas de los depósitos que constiluyen el yacimiento, así como diferentes variables medidas en los restos óseos encontrados han permitido la interpretación paleogeográfica y tafonómica de dicho yacimiento. En el conjunto de los niveles excavados se han encontrado tres acumulaciones de restos óseos superpuestas. No se han hallado diferencias faunísticas significativas entre dichas acumulaciones, tanto en edad como en asociaciones de fauna. La diferenciación de tres niveles fosilíferos se debe principalmente a condicionantes sedimentológicos. Los niveles fosilíferos se formaron en un ambiente palustre-lacustre marginal, preferentemente durante las etapas de bajo nivel de agua cuando predominan las condiciones palustres. Los niveles formados en las etapas de aguas altas, en un ambiente lacustre con producción de carbonatos, son prácticamente estériles. La asociación se produjo principalmente por la acción de depredadorescarroñeros y la concentración de fauna en los alrededores del área palustre. No se han encontrado indicios de participación de corrientes aluviales-fluviales en la reunión de los restos, ni éstos muestran señales de transporte. Es una concentración autóctona con un enterramiento rápido. De cada resto fósil recuperado se midieron varias variables y los datos así obtenidos fueron sometidos a un tratamiento grá́fico y estadístico que proporcionó información significativa para la interpretación de la tafonomía del yacimiento.

Palabras clave: Tafonomía, Vertebrados, sedimentación lacustre y palustre, Pleistoceno Medio, Granada. 


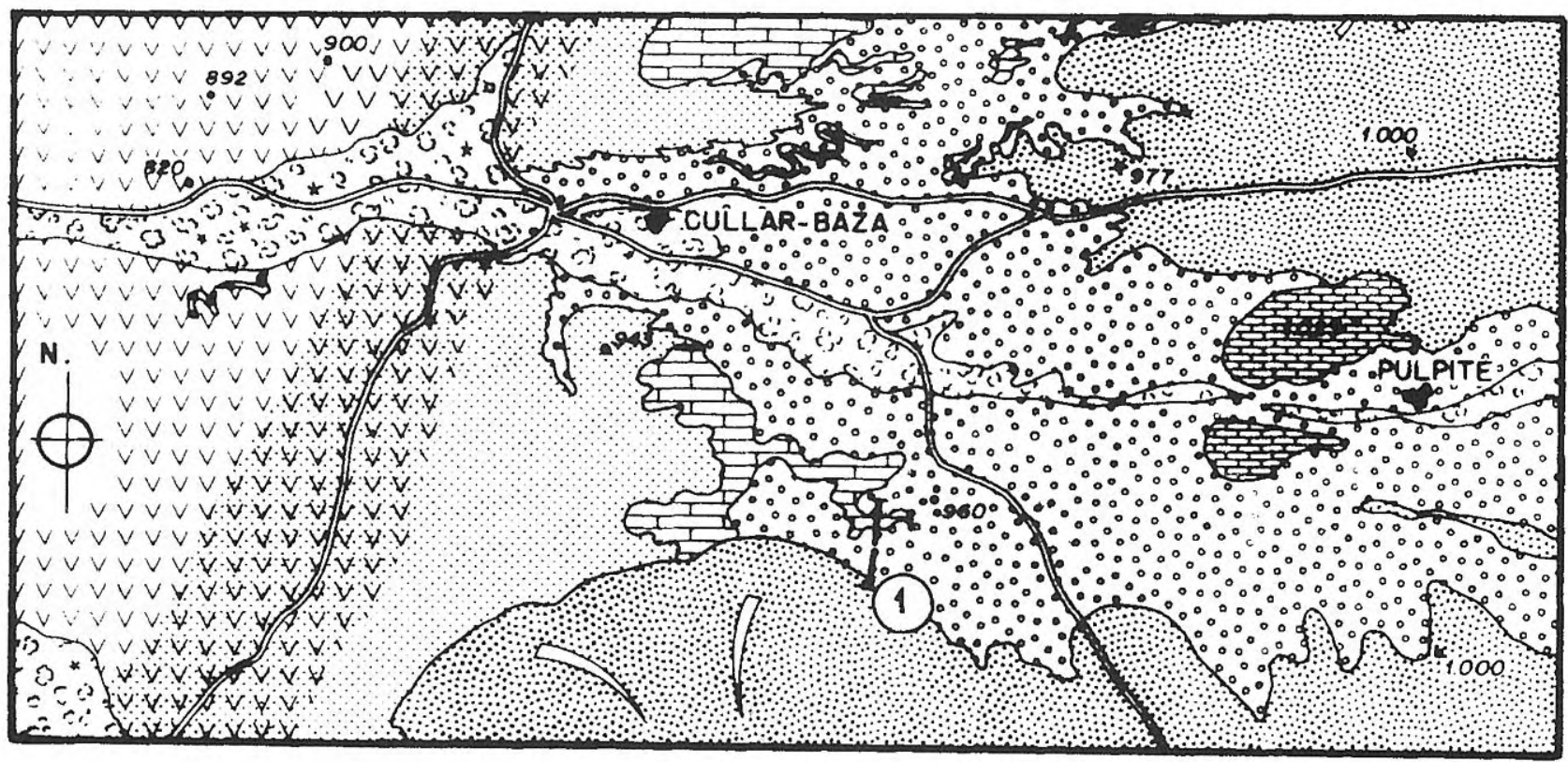

a:b Cultivos, Romblas actuales

Abanicos Aluviales Terminales

$\because \because$ Tramo Conglomerados y Arenas Rojas

Tramo Corbonotodo Superior

I Tramo de Arenos Amarillas

Cambio loteral de focies

vVy Tramo de Dolomías y Yesos

Sustrato. Carbonatos. Complejo Maláguide

(1) Yacimiento Cúllar-Baza

- Serie Cúllar-Baza
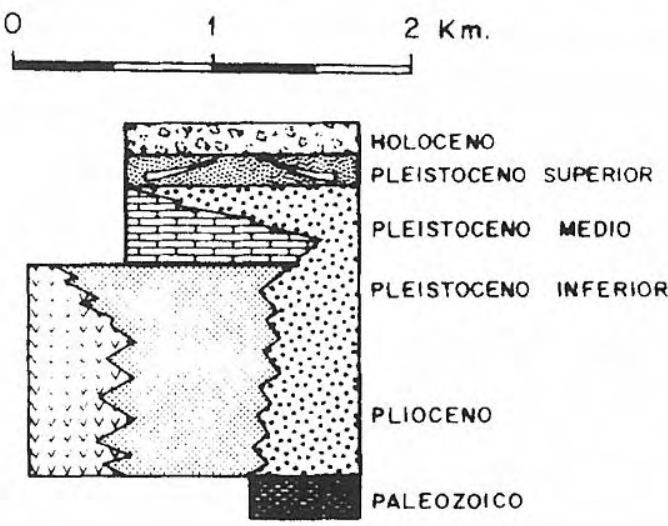

(a)

E

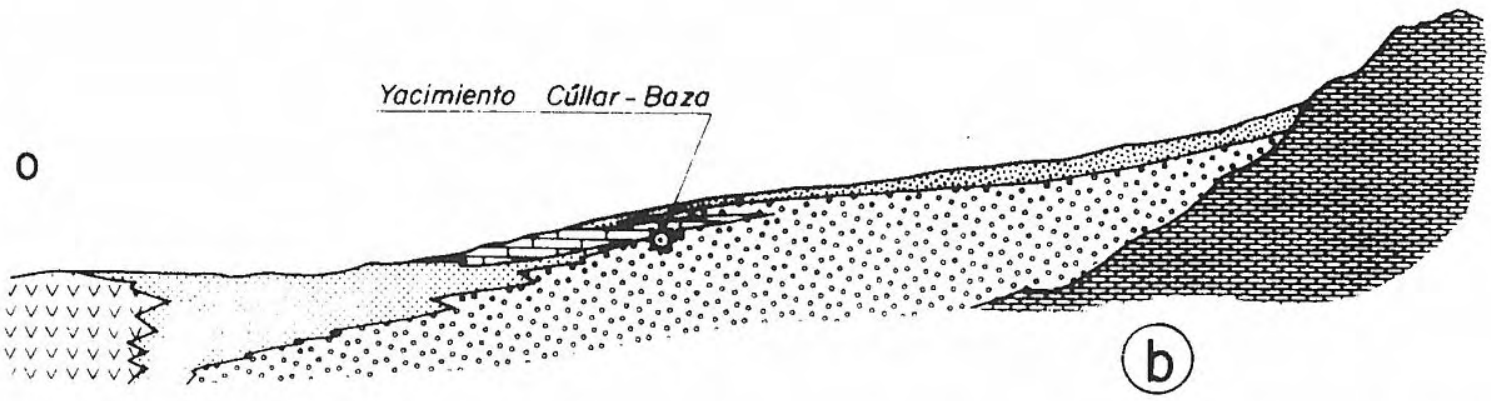

Figura 1. a. Mapa geológico donde se muestra la cartografía a escala 1:50.000 de las unidades estratigráficas diferenciadas (denominadas tramos), la columna estratigráfica regional y la situación del yacimiento de Cúllar de Baza-1. b. Corte esquemático de dirección O-E, a la altura del yacimiento de Cúllar de Baza-1, que muestra las relaciones laterales de los tramos cartografiados en a.

a. Cartography of the informal stratigraphic units mentioned in the text (named "tramos"), scale =1:50,000; local stratigraphic section; Cúllar de Baza-1 site geographical location. b. East-West stratigraphic cross section on the Cúllar de Baza-1 latitude, lateral relationships among the stratrigraphic units are shown. 


\section{INTRODUCCIÓN}

Las especiales características estructurales de la cuenca de Guadix-Baza, situada en una zona tectónicamente activa con una tasa de subsidencia importante, han dado lugar, durante el Plioceno y Cuaternario, a una sedimentación centrípeta y asimétrica alimentada por sistemas de abanicos aluviales que hacia las zonas más deprimidas pasaban a sucesivos ambientes palustres-lacustres. Las características de estos medios sedimentarios y la rápida subsidencia de la cuenca han permitido la formación y conservación de numerosos yacimientos de vertebrados. Aunque recientemente Alberdi et al. (2001) han analizado comparativamente la tafonomía, sedimentología y paleoecología de tres importantes yacimientos de vertebrados continentales situados en esta cuenca (Huélago, Huéscar y Cúllar de Baza-1), consideramos importante la publicación detallada de la tafonomía y sedimentología de Cúllar de Baza-1, que puede contribuir al conocimiento de los mecanismos de formación de yacimientos de vertebrados en cuencas continentales.

El yacimiento de Cúllar de Baza-1 está situado $1 \mathrm{~km}$ al SE de la localidad del mismo nombre (UTM 388-585), provincia de Granada, a una cota de 960 m.s.n.m. Se localiza en la parte oriental de la entidad geográfica y geológica conocida como Depresión de Guadix-Baza y forma parte del numeroso grupo de yacimientos de vertebrados Plio-Pleistocenos descubiertos en ella. Los niveles del yacimiento pertenecen a los afloramientos más surorientales del Tramo Carbonatado Superior (Fig. 1a, 1b), conjunto de carbonatos y limos lacustres-palustres de edad pleistocena que afloran en las proximidades de Cúllar de Baza-1 (Alonso Diago, 1991). Reposan sobre los conglomerados y arenas aluvio-fluviales del Tramo de Conglomerados y Arenas Rojas y corresponden al tramo 9 de la Serie de Cúllar de Baza-1 (Fig. 2).

Este trabajo pretende integrar los datos faunísticos, el análisis sedimentológico detallado de los niveles excavados y la disposición y características de los restos óseos (estado de meteorización, modificaciones diagenéticas, marcas, etc.) con el objetivo de reconstruir el ambiente paleogeográfico del yacimiento y su génesis.

\section{FAUNA Y EDAD DEL YACIMIENTO}

En las excavaciones sistemáticas llevadas a cabo en el yacimiento de Cúllar de Baza-1 se han recuperado un gran número de especies de vertebrados e invertebrados, entre los cuales cabe destacar una importante serie de grandes mamíferos, habiéndose determinado un proboscídeo, tres especies de perisodáctilos, cuatro de artiodáctilos y tres de carnívoros, así como seis especies de micromamíferos (Alberdi et al., 1989b). Se han reconocido también otros grupos de vertebrados: cinco especies de reptiles (Barbadillo,1989); una especie de peces (Doadrio y Casado, 1989) y otra de quelonios (Jiménez Fuentes y Martín de Jesús,1989). En invertebrados se han reconocido nueve especies (Robles,1989). Finalmente, este yacimiento

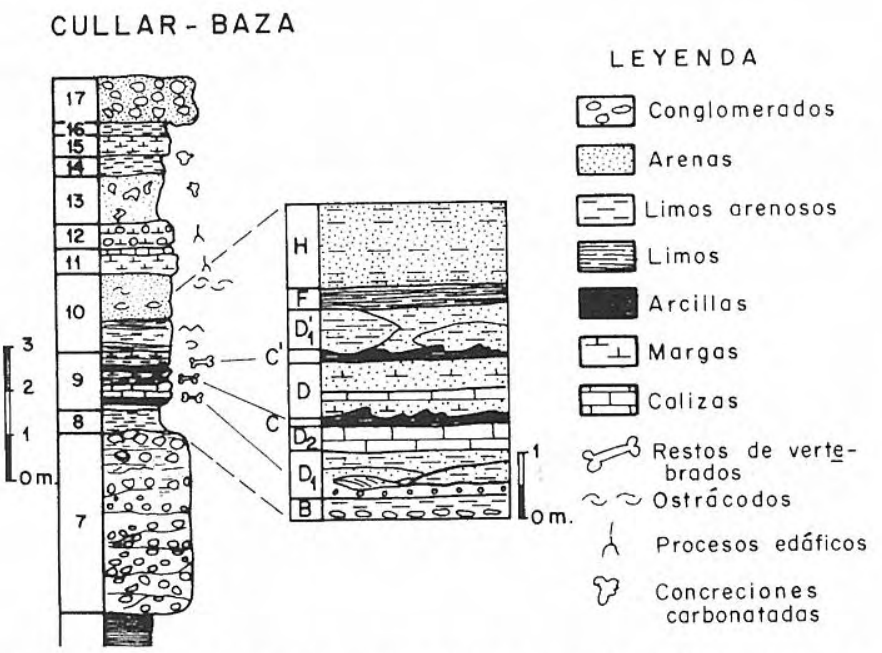

Figura 2. Corte estratigráfico del yacimiento del Pleistoceno Medio de Cúllar de Baza-1 donde están incluidos los niveles de la excavación (Alonso Diago, 1991). Debido al carácter de lentejón de los niveles D2, estos no siempre están presentes en el corte.

Stratigraphic section of Cúllar de Baza-1 site, the microstratigraphy of the excavation is shown as well (Alonso Diago, 1991). Due to the wedge like shape of Level D2, this one is discontinuous along side the cross section.

también ha proporcionado restos de industria lítica, que encajarían dentro del Paleolítico Inferior Antiguo (Vega Toscano, 1989).

Estas faunas permiten situar el yacimiento de Cúllar de Baza-1 al comienzo del Pleistoceno Medio, con una edad en torno a los 700.000 años.

\section{METODOLOGÍA DE LA EXCAVACIÓN}

Se excavó una cuadrícula denominada $\mathrm{B}$, de $24 \mathrm{~m}^{2}$ de extensión (Alberdi et al., 1989a), y el testigo dejado en la excavación anterior de Ruiz Bustos (1976), que se denominó cuadrícula A aunque tuvo una forma irregular (Fig. 3). Las dimensiones de la cuadrícula $B$ son $X=6 \mathrm{~m}$, $\mathrm{Y}=4 \mathrm{~m}$ y $\mathrm{Z}=1,5 \mathrm{~m}$. El eje $\mathrm{X}$ tiene la dirección $\mathrm{E}-\mathrm{O}$ y el eje $\mathrm{Y}$ la $\mathrm{N}-\mathrm{S}$. De las piezas extraídas se tomaron los parámetros espaciales $\mathrm{X}, \mathrm{Y}, \mathrm{Z}$, la longitud máxima del resto en centímetros, la dirección cuando tenía una dimensión dominante y la determinación anatómica del elemento esquelético recuperado.

\section{MICROESTRATIGRAFÍA DEL YACIMIENTO}

Se ha seguido, por razones de uniformidad, la nomenclatura propuesta por Ruiz Bustos en su excavación de 1976, aunque la asignación alfabética de los niveles es aparentemente algo confusa, ya que no es correlativa debido a las variaciones laterales con respecto al corte inicial de referencia (Ruiz Bustos,1976). En ella se asignó 

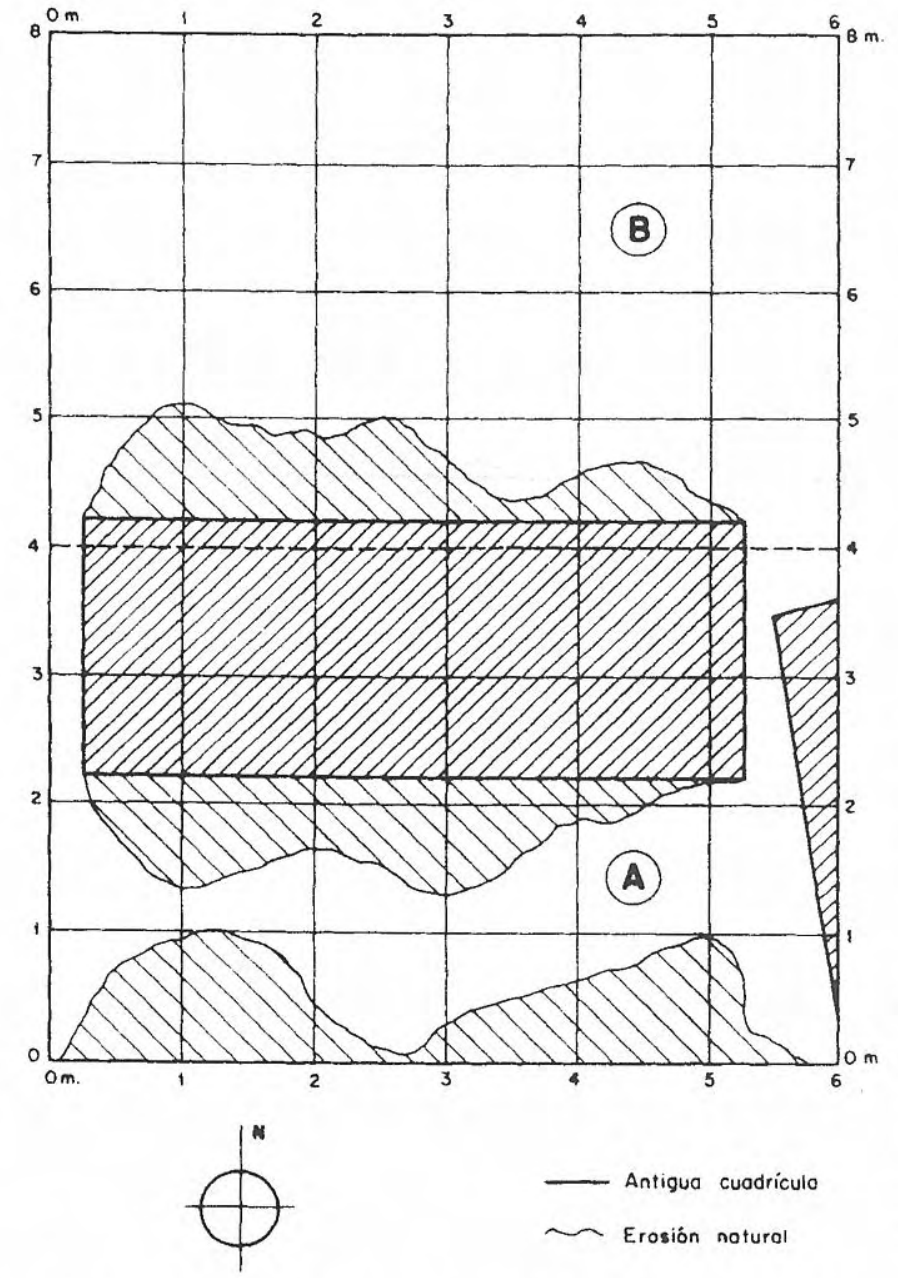

Figura 3. Representación gráfica de las cuadrículas A y B excavadas en Cúllar de Baza-1. El espacio remarcado como Antigua cuadrícula se refiere a la parte excavada por Ruiz-Bustos (1976). Graphic representation of Cúllar de Baza-1 grids $A$ and B. The area labeled as "Antigua cuadrícula" corresponds to the 1976 excavation (Ruiz-Bustos, 1976).

la letra $\mathrm{D}$ a los tramos más o menos carbonatados, y la $\mathrm{C}$ a los limosos arcillosos. De muro a techo se diferenciaron los siguientes niveles (Fig. 4a; Fig. 2):

Nivel B: Potencia 20 a $30 \mathrm{~cm}$. Está formado en la base por un conglomerado de color gris con clastos de mármoles, micaesquistos y cuarcitas. De la mitad del nivel hacia techo pasa a limos verdes con restos de plantas limonitizadas. Este nivel es estéril en vertebrados.

Nivel D1: Potencia de 20 a $80 \mathrm{~cm}$. Comprende limos marrones más o menos carbonatados con forma de lentejón; internamente tienen aspecto masivo o desarrollan laminación de tipo "flasser" preferentemente en la base del nivel. Se ha reconocido estratificación cruzada de pequeña-mediana escala, con fragmentos de gasterópodos en la base de los "sets" (Fig. 4b). La base del nivel está constituida por una acumulación de gasterópodos fragmentados y pequeños trozos de vegetales carbonizados; en el interior del tramo también aparecen gasterópodos dispersos, sin fracturar. Contiene restos de vertebrados.

Nivel D2: Potencia de 15 a $25 \mathrm{~cm}$. Consiste en lentejones discontinuos de calizas blancas con porosidad fenestral y recristalizaciones que se acuñan lateralmente hasta desaparecer, reposando en este caso los limos del nivel C sobre el nivel D1 (Fig. 4a). Contiene restos fósiles muy escasos.

Nivel C: Potencia de 3 a $10 \mathrm{~cm}$. Constituye un nivel centimétrico de arcillas y limos negros o marrones-verdes oscuros que se acuñan lateralmente, llegando a desaparecer. Tiene grandes deformaciones plásticas, contiene abundantes gasterópodos y materia orgánica, los restos de vertebrados son muy numerosos.

Nivel D: Potencia de 30 a $80 \mathrm{~cm}$. Formado por margas y margocalizas blancas arenosas, con gasterópodos enteros dispersos en el interior del nivel; hacia techo aumenta el grado de carbonatación disminuyendo el porcentaje de limo y arena. Tiene deformaciones plásticas y posee escasos restos de vertebrados. Contiene un lentejón de calizas más cementado, de 15 a $20 \mathrm{~cm}$, que destaca en el perfil por su mayor dureza y cohesión. A este lentejón se le llamó D2'.

Nivel C': Potencia 5 a $20 \mathrm{~cm}$. Limos arcillosos negros, masivos y con las mismas características que los del nivel C estratigráficamente inferior.

Nivel D1': Potencia de 30 a $60 \mathrm{~cm}$. Limos arenosos marrones oscuros, masivos y carbonatados, semejantes al nivel D1 inferior.

Nivel F: Potencia $25 \mathrm{~cm}$. Formado por limos verdes con cemento carbonático, tienen aspecto masivo, en general, pero puntualmente se reconoce una laminación horizontal ligeramente ondulada. Es un nivel estéril en cuanto a restos de vertebrados aunque contiene abundantes ostrácodos.

Nivel H: Potencia $170 \mathrm{~cm}$. Consiste en arenas limosas verde amarillentas con laminación ondulada y laminación de "ripples" de oscilación. Tienen alternancia de colores amarillos y verdosos. Es una arena bioclástica por los abundantes restos de ostrácodos que contiene. Sin restos de vertebrados.

Todavía, en la serie local, sobre los niveles excavados del yacimiento, aparecen tres niveles sedimentarios más:

Figura 4. a. Perfil de excavación del yacimiento de Cúllar de Baza-1. Los niveles D2 se acuñan lateralmente llegando a desaparecer. b. Laminación cruzada en el nivel D1 inferior. c. Mandíbula de Equus altidens altidens Reichneau, englobada en una matriz limoso-carbonatada, Nivel D1 inferior. d. Fragmento algal del nivel D2 superior, lámina delgada. e. Arenas bioclásticas con ostrácodos, nivel H, lámina delgada.

a. Cúllar de Baza-1 excavation cross section, D2 levels have wedge like shape. b. Cross stratification inside Level D1. c. Jaw of Equus altidens altidens Reichneau, enclosed in marls, level D1. d. Algal remain from Level D2, thin section. e. Bioclastic sand with ostracode remains, Level H, thin section. 


\section{a}

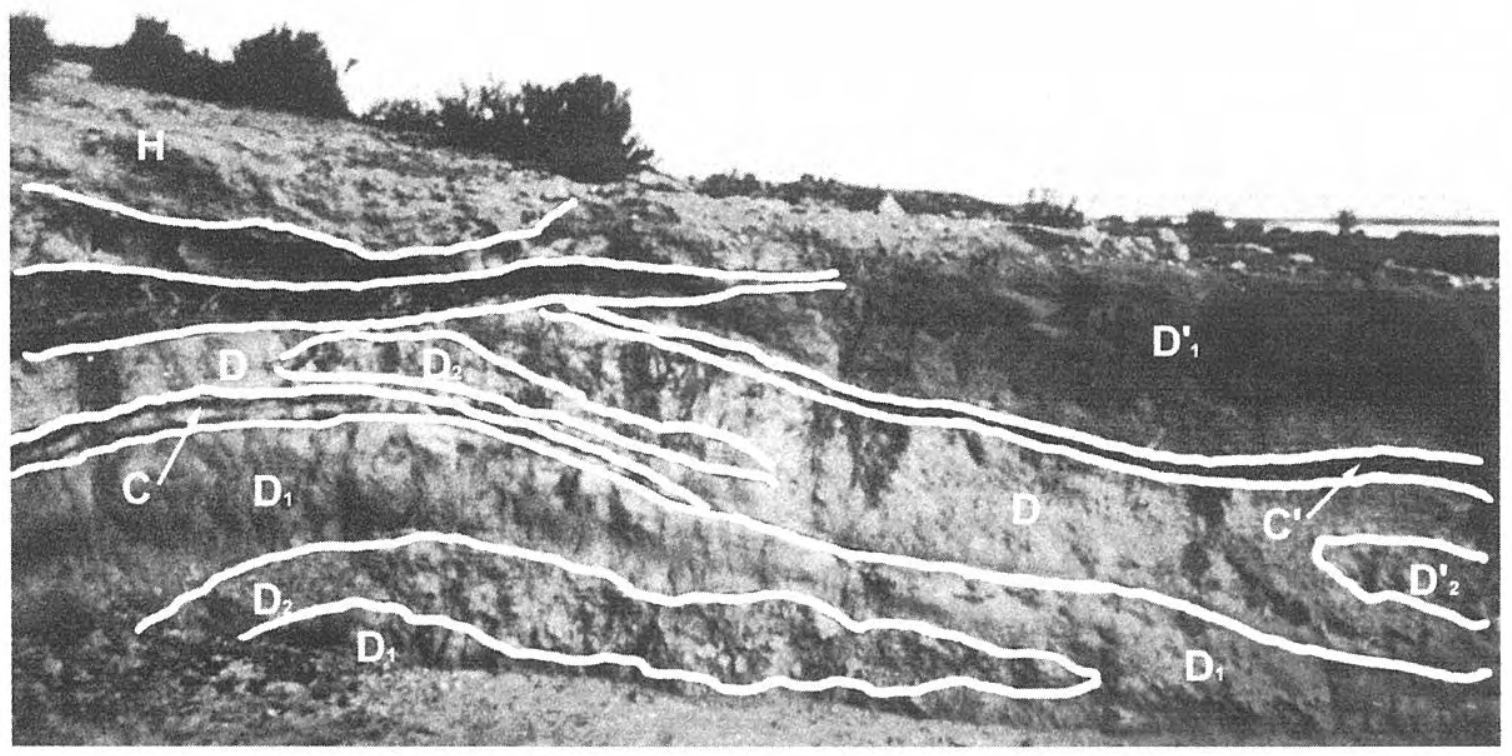

$1 \mathrm{~m}$
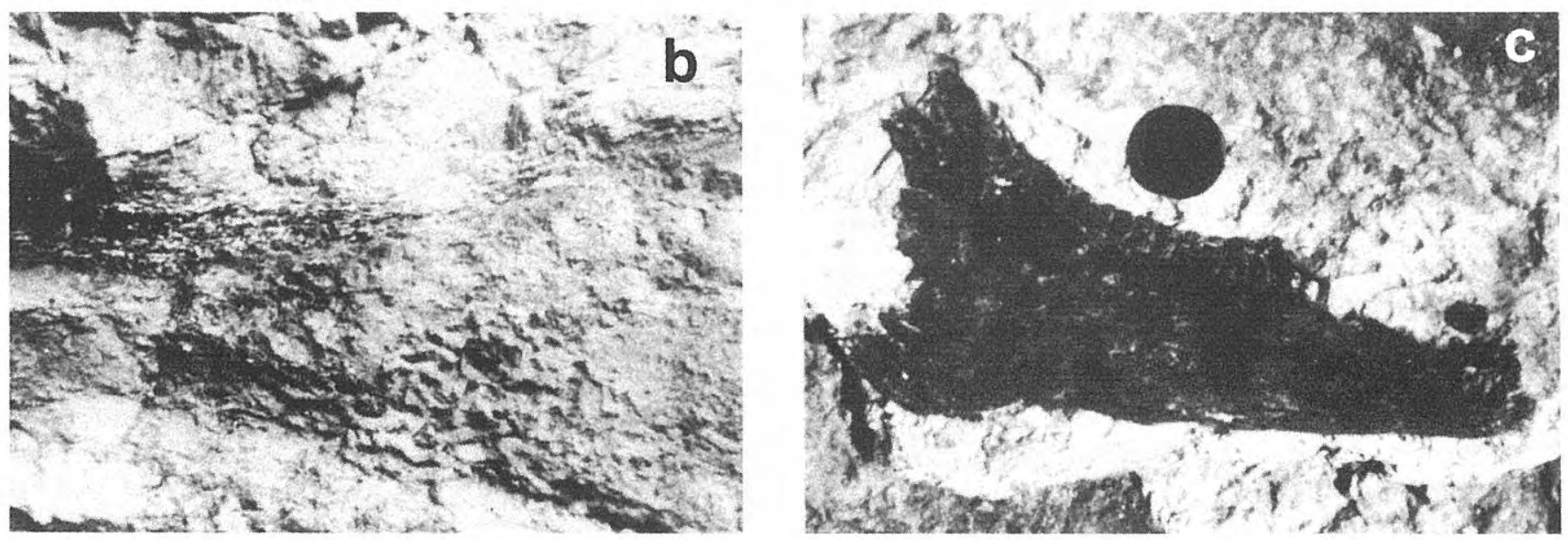

\section{$10 \mathrm{~cm}$}

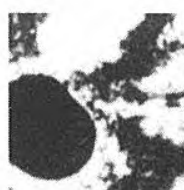

कo

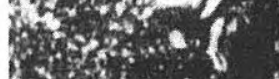

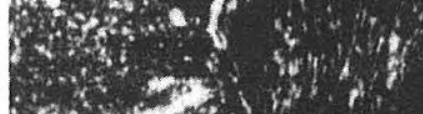

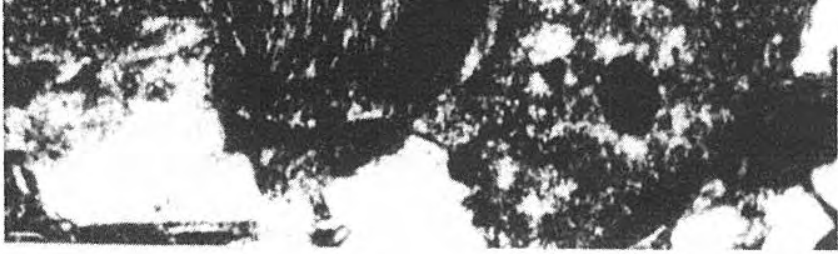

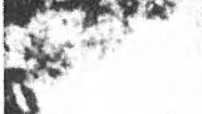

$111 \mu$
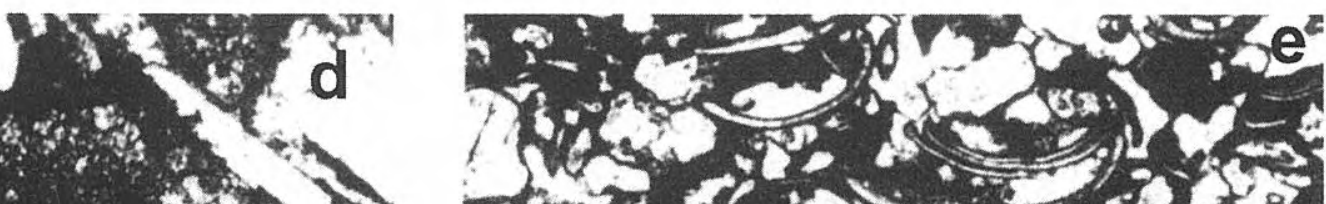
is $x^{2}+2$
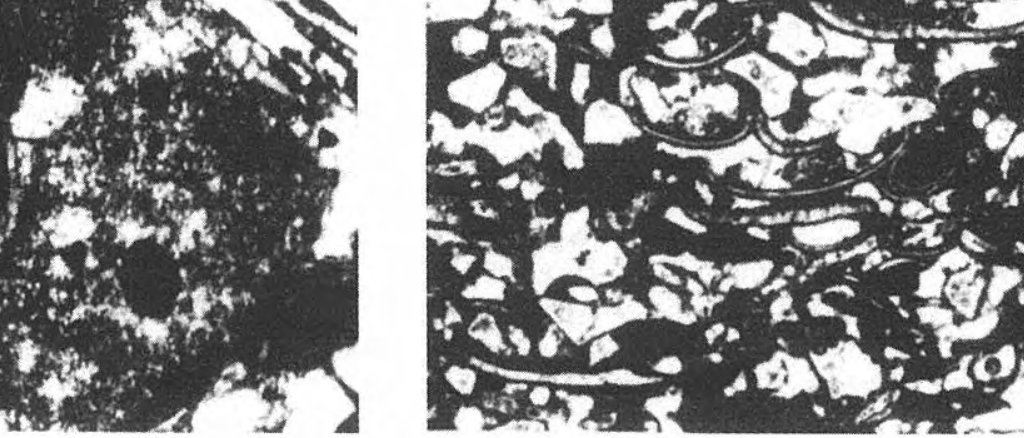
Nivel I: Potencia $30 \mathrm{~cm}$. Margas ocres, masivas, con huellas de raíces limonitizadas. El contacto con el nivel $\mathrm{H}$ es progresivo (Fig. 2, nivel 11).

Nivel J: Potencia $70 \mathrm{~cm}$. Margas blancas, nodulosas, con niveles centimétricos de limos verdosos intercalados (Fig. 2, nivel 12).

Nivel K: Potencia $230 \mathrm{~cm}$. Está formado por alternancias de 20 a $50 \mathrm{~cm}$ de limos verdes y arenas con niveles edáficos (Fig. 2, nivel 13).

En los diferentes niveles detríticos de la excavación, los granos tamaño limo y arena fina están constituidos por cuarzo, clastos de foraminíferos resedimentados y fragmentos de biotitas y micaesquistos indicando un área madre situada hacia el este, en los relieves Alpujárrides y Maláguides de las Sierras de las Estancias.

El estudio de las láminas delgadas de los niveles carbonatados del yacimiento (D, D2), muestra que se trata de limos con cemento carbonático y micritas con restos de ostrácodos, algas (Fig. 4d) y lentículas de yeso preferentemente asociadas a las estructuras algales. Las láminas delgadas de los niveles $\mathrm{F}$ y $\mathrm{H}$ muestran que se trata de limos arenosos y arenas bioclásticas de ostrácodos con laminación horizontal (Fig. 4e). Se conserva un gran porcentaje de valvas de ostrácodos unidas. Los clastos tamaño arena fina-media son de mármoles, cuarzos metamórficos, anfíboles y pizarras. Hay abundante porosidad "bird-eyes" rellena en parte por seudoesparita. En las láminas delgadas de los niveles margosos situados sobre el yacimiento (I, J) se observan limos con abundante cemento micrítico, micritas con estructuras algales, ostrácodos y seudomorfos de carbonato a partir de yeso de hábito lenticular.

\section{AMBIENTES SEDIMENTARIOS Y PALEOGEOGRAFÍA}

En el yacimiento de Cúllar de Baza-1 se han distinguido, de muro a techo, cuatro ambientes sedimentarios sucesivos:

\section{$1^{\text {er }}$ ambiente sedimentario}

El primer nivel de excavación (Nivel B) representa un tránsito entre los conglomerados aluvio-fluviales infrayacentes del Tramo de Conglomerados y Arenas Rojizas y los niveles limosos y carbonatados del yacimiento de Cúllar de Baza-1, que pertenecen ya al Tramo Carbonatado Superior (Fig. 1a, 1b). Indican un cambio progresivo y rápido en la sedimentación sin llegar a ser una ruptura sedimentaria sensu stricto, señalando el comienzo de una nueva etapa sedimentaria, caracterizada por una sedimentación en medios palustres-lacustres. Las abundantes huellas de raíces y los colores grises verdosos de los limos del nivel $\mathrm{B}$ son indicios de un progresivo encharcamiento. Hacia techo de la columna se pasa gradualmente a los niveles D1 y C que representan ya condiciones claramente palustres en ambiente reductor, con déficit de oxígeno y acumulación de materia orgánica, depósito de limos y arcillas carbonosas, y abundantes restos de gasterópodos. Dentro del nivel D1 se reconoce una forma de lecho con estratificación cruzada de limos arenosos, que indica la existencia, al menos esporádica, de corrientes dentro del sistema palustre. No obstante, no se encuentran materiales alóctonos más gruesos que el tamaño arena fina, índice de la escasa competencia de aquellas corrientes. Estos niveles son fosilíferos, especialmente el $\mathrm{C}$, donde las condiciones de encharcamiento palustres fueron más marcadas, llegando incluso a constituir pequeños niveles de lignitos. Los límites entre los niveles D1 y C son muy irregulares y ondulados (Fig. 4a), provocados por la plasticidad de un medio saturado de agua e inducidas probablemente, además, por la inestabilidad tectónica de la cuenca (Alonso Diago, 1991).

\section{$2^{\circ}$ ambiente sedimentario}

El paso de los niveles marrones y negruzcos D1 y C al nivel D de margas y margocalizas blancas representa un nuevo cambio en el medio sedimentario hacia condiciones lacustres con marcada lámina de agua: desaparecen el ambiente reductor y el entramado de raíces, comenzando la formación de margas y calizas. En medios lacustres actuales se ha observado cómo un descenso de la lámina de agua provoca la interrupción de la formación de margas y calizas y favorece la colonización por la vegetación acuática no algal, con la consiguiente acumulación de materia orgánica (Weninger y Mc Andrews, 1989). El nivel $\mathrm{D}$, con predominio de la sedimentación carbonatada, representa el momento de mayor expansión y altura del nivel del agua, que venía creciendo con ligeras pulsaciones desde el techo del nivel B. Los lentejones de calizas que se destacan dentro de él (denominados nivel D2) muestran mayor abundancia de restos de algas que los otros niveles, a las que se debe el mayor grado de carbonatación, ya que con su actividad vital formaron núcleos de precipitación de carbonato cálcico.

\section{$3^{\text {er }}$ ambiente sedimentario}

Tras el depósito del nivel D, acaeció un descenso relativamente rápido del nivel del agua, pasando de nuevo a condiciones palustres la zona del yacimiento. Se propició la formación de una nueva capa de limos y lignitos (C') y el último nivel D1. Estos niveles contienen abundantes restos fósiles.

\section{$4^{\circ}$ ambiente sedimentario}

Los niveles $\mathrm{F}$ y $\mathrm{H}$ son ya estériles y representan un cambio importante en el régimen de sedimentación, pasándose de un ambiente palustre y lacustre carbonatado marginal a un régimen lacustre más abierto, bien oxigenado, con sedimentación detrítica de arenas y limos. El nivel H, concretamente, está formado por arenas bioclásticas de ostrácodos con "ripples" de oscilación y laminación lenticular. Responden a una expansión hacia el E del borde del sistema lacustre del Tramo Carbonatado Superior, con el que conectaba lateralmente la zona palustre (Fig. 5).

Finalmente, los niveles situados sobre el perfil de excavación (I, J) se formaron durante una nueva etapa de sedimentación carbonatada lacustre más somera, 


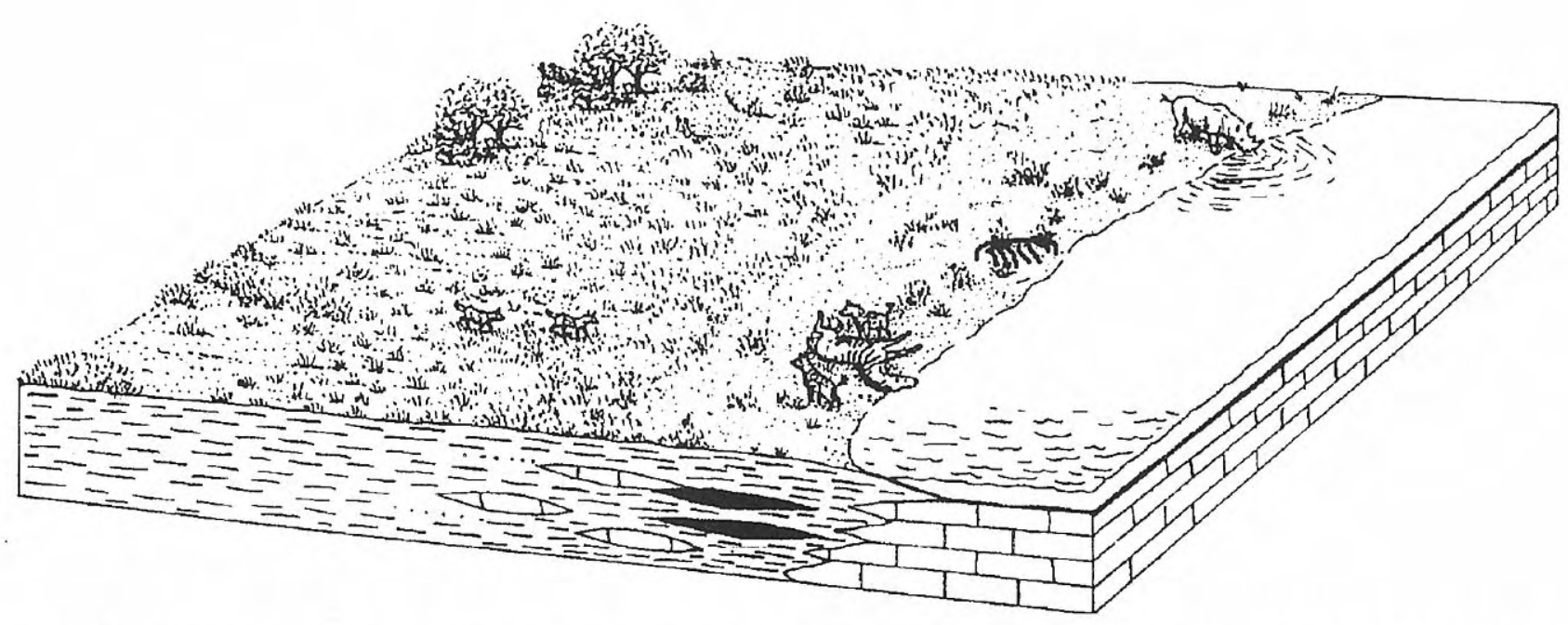

Figura 5. Modelo sedimentario y condiciones de formación del yacimiento de Cúllar de Baza-1 (modificado de Alberdi et al., 2001).

Reconstruction of the Cúllar de Baza-1 sedimentary environment (modified from Alberdi et al., 2001).

relacionada con una paulatina regresión de las aguas. Por último, los sedimentos aluviales y depósitos edafizados del Nivel K representan la desaparición definitiva del ambiente palustre-lacustre en la zona del emplazamiento del yacimiento de Cúllar de Baza-1.

En resumen, en el conjunto de niveles estudiados, se distinguen cuatro ciclos expansivos-retroactivos en relación con la lámina de agua, todos ellos relacionados con un área restringida marginal lacustre que varía en el tiempo:

- Aumento progresivo (ciclo expansivo) de la lámina de agua pasando por condiciones palustres de encharcamiento (con acumulación de restos de vertebrados en los niveles C y D1) hasta alcanzar posteriormente condiciones lacustres marginales (nivel D, D2) con escasa acumulación de restos de vertebrados.

- Descenso de la lámina de agua (ciclo retroactivo) para volver a condiciones palustres: niveles C'y D1' con abundantes restos de vertebrados.

- Fuerte aumento de la lámina de agua (expansión más pronunciada) con condiciones lacustres abiertas (niveles F y especialmente $\mathrm{H}$ ) y sin restos de vertebrados.

- Descenso definitivo (regresión) del nivel de la lámina de agua volviendo a condiciones lacustres marginales (niveles I, J) y finalmente sedimentos aluviales y edafizaciones (nivel K).

Ni las características sedimentarias ni la fauna indican un ambiente fuertemente salino en el área del yacimiento, pero no se puede descartar una cierta salinidad marcada por la presencia de determinadas especies de ostrácodos (Civis, 1989). Los gasterópodos encontrados son una asociación de especies higrófilas y mesófilas: gasterópodos muy higrófilos que habitan al borde de masas de agua o en sus proximidades y gasterópodos que habitan biotopos herbáceos abiertos, sin cobertura arbórea, con amplia tolerancia a las variaciones de humedad y temperatura (Robles, 1989). En cuanto a la asociación faunística de macromamíferos, parece indicar áreas abiertas escasamente arboladas (Alberdi et al.,
2001). Los pequeños cristales de yeso lenticular o seudomorfos de calcita a partir de cristales de yeso, que aparecen dispersos tanto entre los limos como entre las margas y carbonatos, estarían más relacionados con la descomposición de plantas verdes que con aguas salinas en zonas de alta evaporación (Cody, 1979). Las especies de peces presentes toleran grandes diferencias de temperatura y oxígeno disuelto, pero no viven en zonas con altos contenidos en sales disueltas (Doadrio y Casado, 1989).

Los niveles lacustres del yacimiento conectaban hacia el E con niveles aluviales del Tramo de Conglomerados y Arenas Rojas, y hacia el $\mathrm{O}$ con niveles lacustres del Tramo Carbonatado (Fig. 1b). En la Fig. 5 se representa un esquema del ambiente de formación del yacimiento. Las únicas direcciones de paleocorrientes que se han podido medir sobre la inclinación de los "sets" de estratificaciones cruzadas indicarían una procedencia E, dato que, aunque puntual, coincide con la tendencia general de las paleocorrientes del Tramo de Conglomerados y Arenas Rojas dentro del que está intercalado el yacimiento.

Desde un punto de vista tafonómico y en función de lo expuesto, el yacimiento de Cúllar de Baza-1 se puede clasificar según el ambiente de formación dentro del grupo D de Bishop (1980), correspondiente a yacimientos situados en cuencas interiores y trampas, y dentro de éste, en los subgrupos de pantanos y ambientes lacustres.

\section{ESTUDIO DE LOS RESTOS ÓSEOS}

\section{METODOLOGÍA}

Se extrajeron un total de 218 piezas en la cuadrícula B y 108 en la A. Se ha utilizado el programa comercial STATGRAPHICS que permite realizar una gran variedad de medidas estadísticas, con la ventaja añadida de que realiza gráficos bi- y tridimensionales, que reproducen la 
situación de cada resto óseo en las cuadrículas, con variaciones casi ilimitadas. La matriz de datos (Alonso Diago, 1991, Anexo) se elaboró en un fichero de tipo ASCII y se importó al programa STATGRAPHICS según el procedimiento señalado en la sección "Data Managements" del programa. Cada resto tenía una serie de parámetros: posición espacial en la cuadrícula (X, Y, $\mathrm{Z}$ ), dimensiones (longitud, anchura, altura) y variables no numéricas o contingentes, que fueron las siguientes:

Tipo de elemento esquelético, según los códigos: $1=$ esquirlas (trozos de hueso que no se pueden identificar anatómicamente), 2 = dientes sueltos, 3 = huesos largos (diáfisis, metápodos, fémures...), 4 = huesos cortos (astrágalos), 5 = huesos planos (escápulas), $6=$ mandíbulas y cráneos, $7=$ cuernas.

Estado de meteorización. De este parámetro hemos adoptado tres de las cinco categorías definidas por Behrensmeyer (1978) para acumulaciones óseas actuales, adaptándolas a los aspectos reconocibles en los huesos fósiles en una primera fase de estudio. Estas tres categorías son las siguientes: código 1 = estado de meteorización 1 (huesos con superficies lisas, grietas superficiales que no crean irregularidades, sin pérdida de las capas más externas); código 2 = estado de meteorización 2 (agrietamiento medio, ligeras descamaciones, faltan partes de la superficie); código $3=$ estado de meteorización 3 (superficie muy irregular por agrietamiento profundo, pueden aflorar en esta superficie algunas porciones de las capas interiores).

Marcas de raíces. Se han establecieron los códigos: 1 $=$ presencia, 2 ausencia.

Los restos presentaban un color prácticamente uniforme, marrón rojizo oscuro.

Se escogieron tres tipos de programas: gráficos bi- y tridemensionales de proyección espacial (opción denominada "Plotting Functions"), tabulaciones cruzadas o tablas de contingencia para las variables no numéricas (opción denominada "Crosstabulation"), y comparación de medidas de los restos (opción "Estimation and Testing"). Con respecto a las primeras, el objetivo era comparar estadísticamente por parejas los datos computados de los restos para las variables no numéricas: nivel, tipo de hueso, estado de meteorización y marcas de raíces. Las tablas nos mostrarían si existían relaciones entre estas variables o están distribuidas al azar. Tanto si las variables están relacionadas como si no están, indicarían importantes pistas para la interpretación de la tafonomía del yacimiento. La comparación de medias entre los huesos se hizo contrastando la media de tamaño entre niveles con el objetivo de obtener datos sobre los agentes acumuladores.

\section{PORCENTAJES}

\section{Tipo de elemento esquelético}

El 57\% de las piezas extraídas corresponde a esquirlas, es decir, fragmentos de hueso que ya estaban fragmentados y disgregados con anterioridad al enterramiento. El siguiente en importancia son los huesos largos $(16,6 \%)$, cráneos y mandíbulas $(8,6 \%)$ y dientes sueltos $(9 \%)$. El menor porcentaje corresponde al grupo de huesos planos y redondos, $2,1 \%$ y $3,7 \%$, respectivamente. Tres datos son especialmente significativos con respecto a estos porcentajes: 1) más de la mitad de los restos fueron fragmentados por algún agente físico, químico o biológico antes de ser enterrados; 2) el alto porcentaje de cráneos y mandíbulas con respecto a dientes sueltos; 3) los elementos esqueléticos menos representados corresponden a costillas, vértebras y escápulas. Las implicaciones tafonómicas de esto se analizan posteriormente, pues se necesitan otras consideraciones aún no expuestas.

\section{Estado de meteorización}

En cuanto al estado de meteorización, de las tres categorías definidas en el comienzo de este apartado, el $68 \%$ están en el estado 1 , el $20 \%$ en el 2 y el $12 \%$ en el 3. Las superficies son lisas, sin agrietamientos ni descamaciones, salvo en un porcentaje muy pequeño.

\section{Marcas de raíces}

Un 22\% de los restos mostraban moldes de un entramado milimétrico de pequeñas raíces. Mas de las tres cuartas partes de las piezas no tienen señales de raíces $(78 \%)$.

\section{Fracturas, incisiones y abrasiones}

La acción de carroñeros se identifica inequívocamente en algunos restos principalmente en esquirlas, y podría haber sido desarrollada al menos por las especies de cánidos e hiénidos encontradas en el yacimiento. Consiste en depresiones redondas o perforaciones en la superficie del hueso (Figs. 6a, 6c, 6e), usualmente pequeñas $(5-10 \mathrm{~mm})$, que son producidas indudablemente por dientes de carnívoros (Hill, 1980) o bien corresponden a bordes fracturados de forma aserrada (Figs. 6b, 6d), producidos por mordiscos de depredadores (Brain, 1981). A esto cabría añadir los coprolitos encontrados en la excavación de 1976. También esta actividad sería responsable de, al menos, parte de la fracturación en fresco ("greenbone") de las esquirlas, reconocible porque produce fracturas alabeadas, cuya superficie es oblicua a la del hueso (Hill, 1980), Figs. 6f, 6g. El material estaba en un estado poco consolidado, por

Figura 6. a. Fragmento de diáfisis con marcas de dientes dejadas por depredadores-carroñeros. b, d. Esquirlas con bordes dentados atribuibles a depredadores-carroñeros. c, e. Fragmentos con depresiones redondeadas atribuibles a marcas de dientes. f, g. Esquirlas con fracturas alabeadas que se producen preferentemente cuando el hueso está fresco. La escala representa un centímetro en todas las piezas.

a. Diaphysis splinter with predators-scavengers teeth marks. b, d. Splinters with crenulated edges attributed to scavengers-predators chewing. c, e. Splinters with rounded marks attributed to teeth marks. f, g. Splinters with greenbone fracturation, characterized by warped edges. The scale always represent 1 centimetre. 


\section{a}
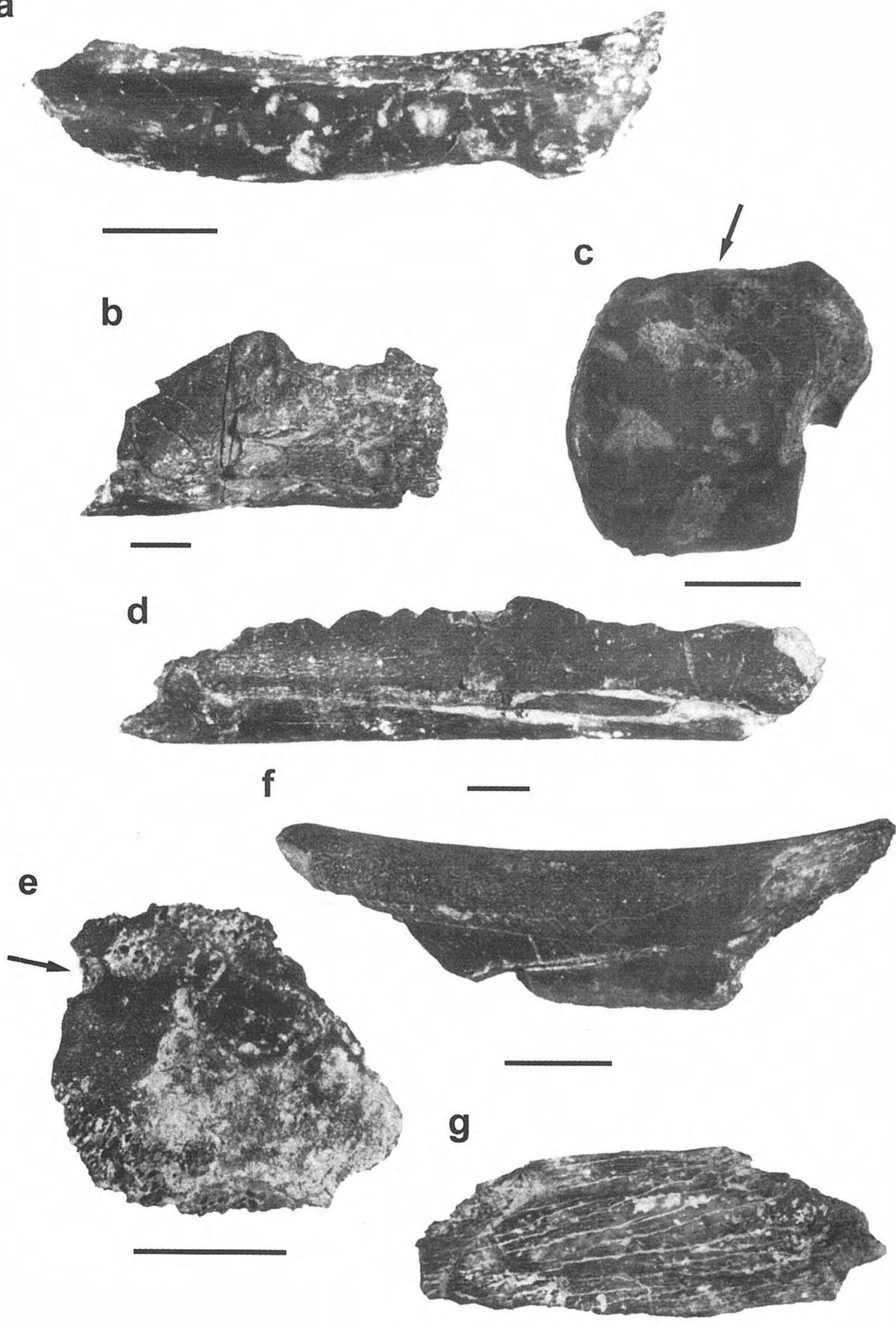

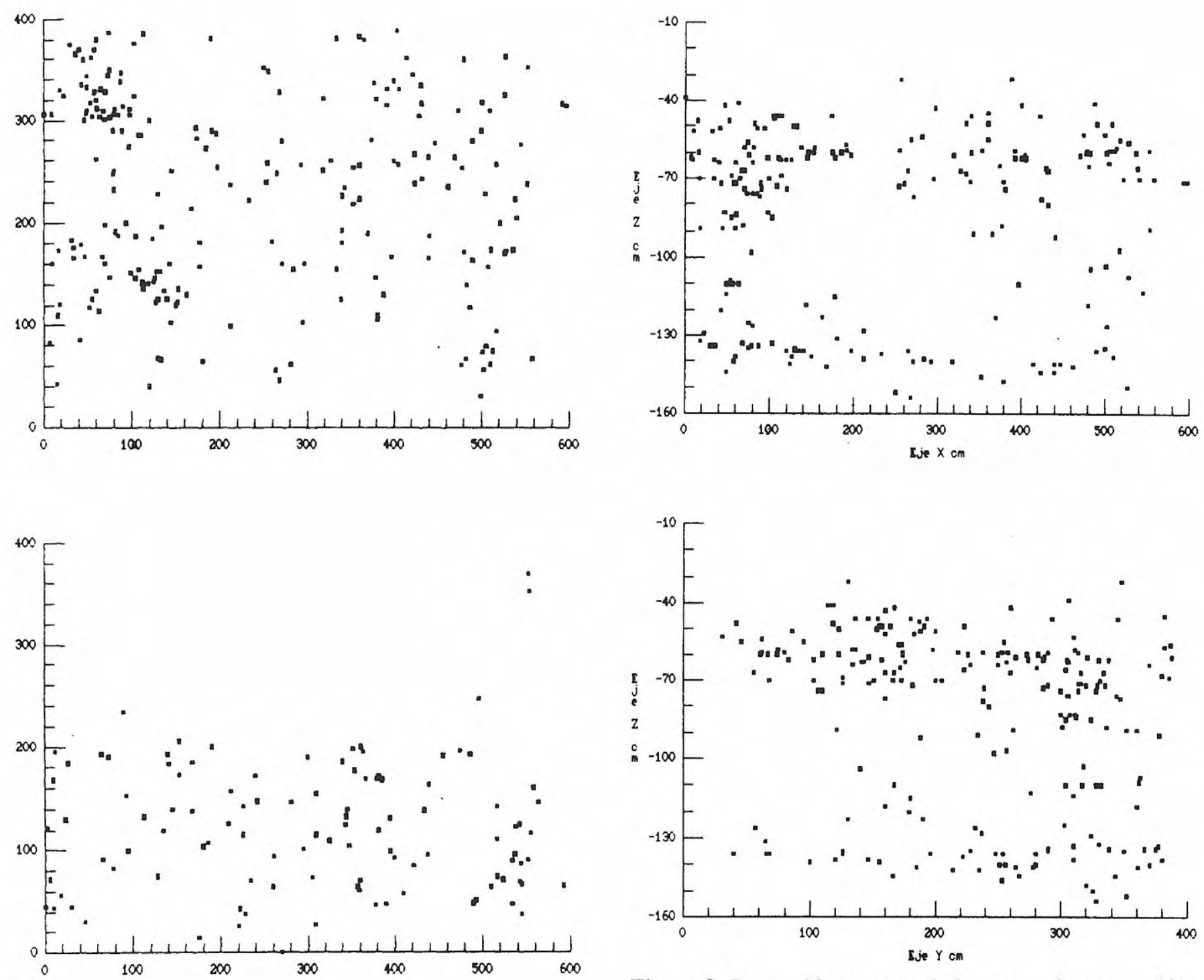

Figura 7. Proyecciones en planta del total de los restos óseos extraídos de las cuadrícula B (arriba) y A (abajo) del yacimiento de Cúllar de Baza-1. Eje X en abscisas e $\mathrm{Y}$ en ordenadas, ambos en centímetros.

Horizontal distribution of the totality of bone remains recovered from grids $B$ (top) and $A$ (bottom), Cúllar de Baza-1 site. X-axis in abscissa and $Y$-axis in ordinate, both in centimetres.

lo que, a pesar de las precauciones, resultó difícil la extracción de las piezas sin que resultaran fracturadas. Sin embargo, en aquellas piezas con buena consistencia, fue posible reconocer, cuando existía, la fracturación previa a la fosilización (por el color de la superficies de la fractura), observándose que las fracturas producidas durante la recuperación del resto fósil pueden mostrar una coloración distinta, generalmente más clara, que la superficie del hueso.

No se han reconocido restos resedimentados, aunque un pequeño fragmento que tiene las superficies llamativamente pulidas, podría haberse originado por

Figura 8. Proyección en corte de los restos óseos extraídos de la cuadrícula B del yacimiento de Cúllar de Baza-1: según el eje $X$ (arriba) y según el eje $Y$ (abajo), siendo el eje $\mathrm{Z}$ la profundidad vertical del perfil.

Vertical distribution of the totality of bones from Cúllar de Baza-1 (grid B), along X-axis (top) and $Y$-axis (bottom), Z-axis represents vertical depth.

acción de corrientes de agua con arcillas. La aparición de restos en conexión anatómica, que aunque esporádicos están repartidos en todos los niveles, es otro indicio del escaso o nulo transporte que sufrieron éstos. Es factible que la desarticulación de los esqueletos en huesos aislados o en conjuntos en conexión anatómica se deba a la acción de depredadores y carroñeros como causa primera, incluyendo la posible actividad humana cuyos restos líticos son patentes en el yacimiento.

\section{GRÁFICOS BI- Y TRIDIMENSIONALES}

\section{Gráficos bidimensionales}

Para la confección de estos se han utilizado los gráficos "X-Y Plots" combinados con los operadores 

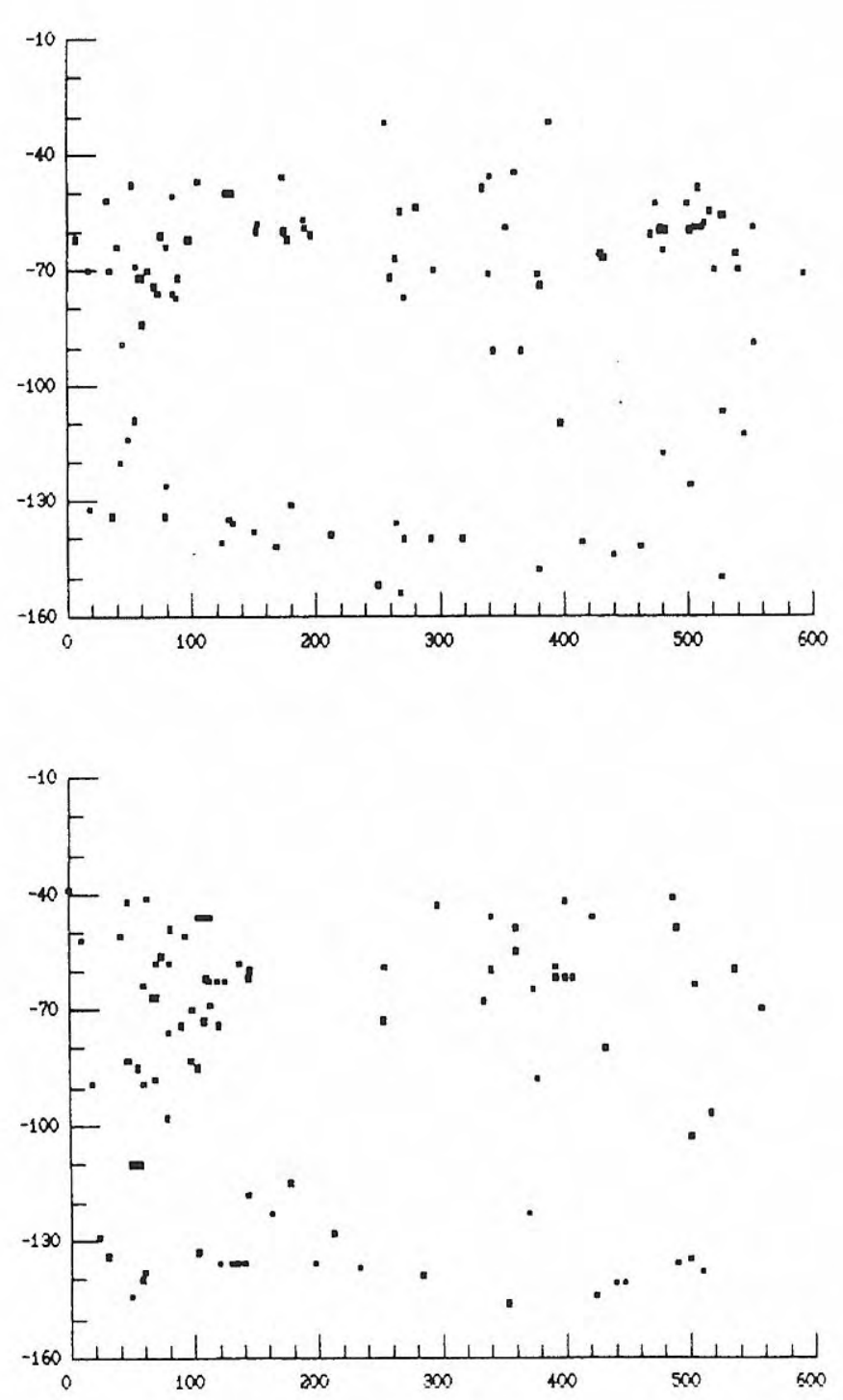

Figura 9. Proyección en corte de los restos óseos de la cuadrícula B, del yacimiento de Cúllar de Baza-1: elemento esquelético esquirla (arriba) y restantes elementos esqueléticos (abajo). Eje X en abscisas y $\mathrm{Z}$ en ordenadas, ambos en centímetros.

Vertical distribution of selected bones from Cúllar de Baza-1 (grid B), splinters only (top), totality of bones but splinters (bottom). X-axis in abscissa and Z-axis in ordinate, both in centimetres.

SELECT y EQ (equivalente), NE (no equivalente) < (menor que) $>$ (mayor que). Estos operadores combinados permiten una selección de los restos que se representan en el gráfico (ejes $\mathrm{X}, \mathrm{Y}, \mathrm{Z}$ ) según una tercera variable que puede ser T (tipo de hueso), o M (estado de meteorización). Los resultados obtenidos se resumen a continuación:

- En las proyecciones en planta X-Y, no se observan estructuras espaciales de distribución reconocibles por niveles. La proyección total es poco significativa ya que se suman restos acumulados en diferentes condiciones sedimentarias (Fig. 7); se observa, no obstante, en la cuadrícula B una mayor concentración de restos alrededor del punto $\mathrm{X}=60 \mathrm{Y}=300$, que coincide con la proximidad en el perfil de dos niveles C (limos negros) que lateralmente se acuñan. Esta mayor concentración no responde a un tipo de hueso en particular.

- En las secciones con respecto a la profundidad (Fig. 8), se hace patente, en cambio, la mayor concentración preferente en dos niveles a una profundidad entre $40 \mathrm{~cm}$ y $80 \mathrm{~cm}$ y entre $120 \mathrm{~cm}$ y $140 \mathrm{~cm}$, aunque existan algunos restos esparcidos a otras profundidades. Contrastando esto con los niveles litológicos, se observa que estos coinciden con los niveles de limos palustres $\mathrm{C}$ y los niveles limoso carbonatados D1. La disposición no varía sustancialmente cuando sólo se imprimen uno o varios de los elementos esqueléticos (Fig. 9). En cuanto a la mayor concentración por niveles, el $48 \%$ de los restos se concentra en los niveles D1+C1 inferiores, el $23 \%$ en el D y el $30 \%$ en los D1 '+C' superiores. La densidad mayor corresponde a los niveles D1'+C' superiores, donde se encuentran más de la cuarta parte en una potencia de sedimentos de 15 a $20 \mathrm{~cm}$. Le siguen, con valores decrecientes de concentración, los niveles D $1+C$ inferiores y finalmente el D.

\section{Gráficos tridimensionales}

Estos gráficos son un complemento a los anteriores; en ellos se observan de nuevo los dos niveles de acumulación con un máximo de restos, casi una nube, en el nivel D1' superior (alrededor de $40 \mathrm{~cm}$ de profundidad) y valores de $\mathrm{X}$ alrededor de $1 \mathrm{~m}$ (Fig. 10). Tampoco hay una disposición preferencial de unos restos frente a otros según las variables tipo o estado de meteorización.

\section{TABLAS DE CONTINGENCIA}

En la matriz de datos, los códigos de los niveles litoestratigráficos, que originalmente eran letras, se transformaron en números por necesidades del programa; las equivalencias establecidas son: código $1=$ nivel D1' y C' superiores, código $2=$ nivel $\mathrm{D}$, código $3=$ nivel $\mathrm{D} 1$ y $\mathrm{C}$ inferiores. Se ha eliminado el nivel D2 que contenía únicamente 2 piezas.

\section{Tabulación cruzada de Nivel frente a Tipo}

Se buscaba una distribución preferente de algunas piezas anatómicas dependiendo de los niveles. Los restos de fragmentos de huesos, esquirlas, representan el tipo dominante entre las piezas extraídas (57\%); a continuación, los huesos largos representan un 16,6\%, cráneos y mandíbulas un $8,6 \%$, y dientes sueltos un $9 \%$; en porcentajes menores se encuentra el grupo de huesos planos $(2,1 \%)$ y el de huesos redondos $(3,7 \%)$. Ante esta desigualdad, se exploraron varias posibilidades: la primera fue subdividir la categoría 2 (dientes) por grupos de fauna. Los resultados indicaron que no había una relación entre las dos variables, pero había un gran número de celdillas en las tablas con valores esperados muy pequeños. Para eliminar esto, se optó por reagrupar de nuevo todos los dientes en una sola categoría, y, finalmente, todos los restos se reagruparon en las tres 

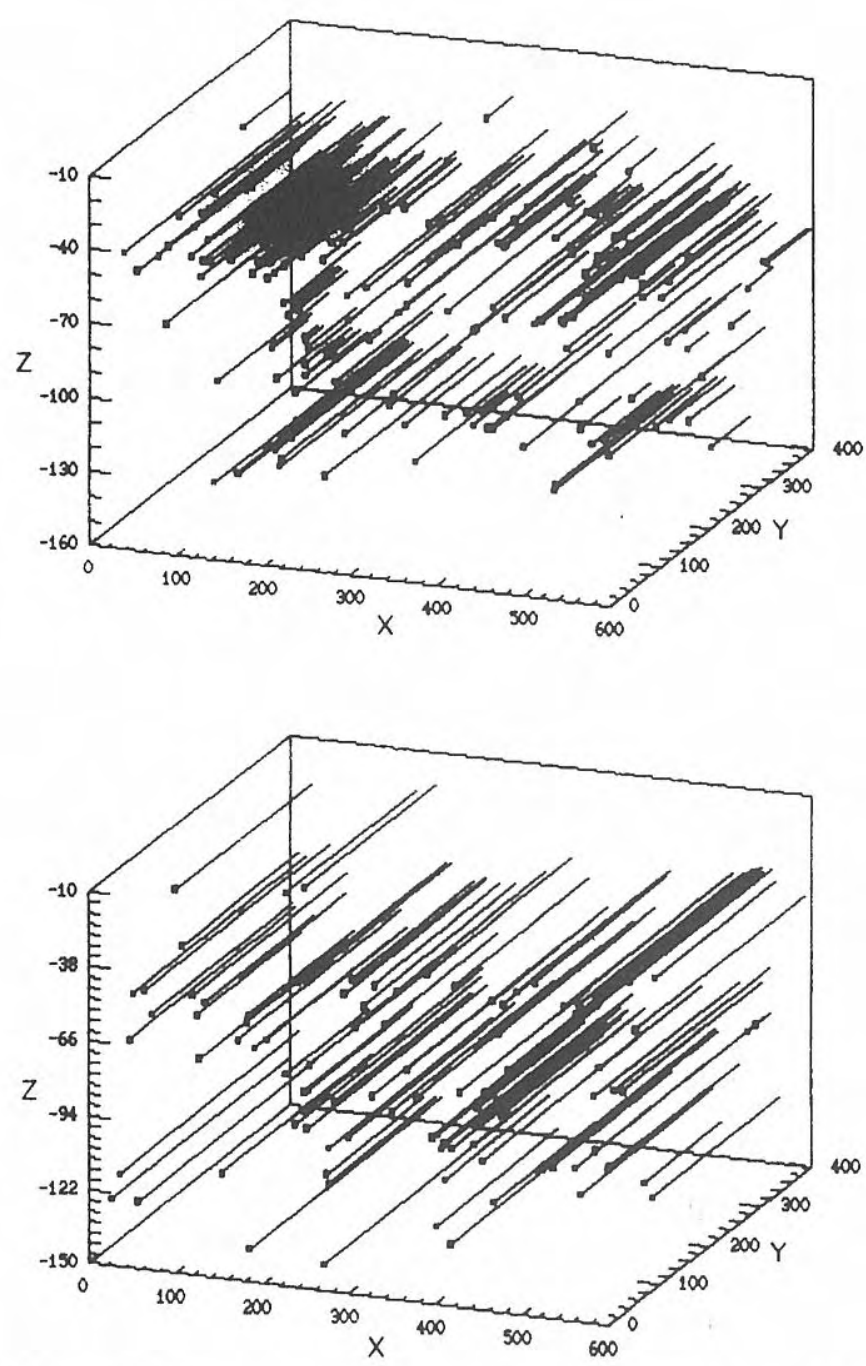

Figura 10. Diagramas tridimensionales de la situación espacial de los restos óseos del yacimiento de Cúllar de Baza-1: cuadrícula B (arriba) y cuadrícula A (abajo). En abscisas el eje X, Z representa la profundidad vertical del perfil. Todos en centímetros.

Three-dimensional projection graphs that represent the spatial distribution of bones from Cúllar de Baza-1, grid B (top), grid A (bottom), X corresponds to the axis of abscissas, $Z$ represents the grid vertical depth. All in centimetres.

categorías con probado comportamiento diferente ante el transporte hidráulico (Voorhies, 1969): los que se mueven con corrientes muy débiles y son transportados incluso por flotación (costillas, vértebras, escápulas), los que tienden a moverse más tardíamente que los primeros (huesos alargados, como fémur, tibia, metápodos), y los que tienden a resistir el transporte (cráneos, mandíbulas). En todos los casos, los resultados tenían una probabilidad de error de un $50 \%$ si se afirma que las variables están relacionadas. Es decir, parece que no hay una selección de piezas anatómicas según los niveles litológicos.

\section{Nivel frente a Meteorización}

El 68\% está en el estado de meteorización 1, el $20 \%$ en el estado 2 y el $12 \%$ en el estado 3. Es decir, la mayoría de los restos aparecen con las capas exteriores y la superficie sin dañar.

No hay diferencias en cuanto al estado de meteorización de los restos con respecto al nivel en que aparecen (Tabla 1). El test del $\chi^{2}$ tiene un nivel de significación semejante al cruce anterior, 0,59 (59\% de probabilidad de error, cuando lo máximo admitido es $5 \%$ ).

\section{Nivel frente a Raíces}

Más de las tres cuartas partes de las piezas no tienen señales de raíces $(78 \%)$, mientras que el resto (22\%) sí las muestran; éstas últimas no se acumulan preferentemente en los niveles superiores de excavación, relativamente próximos al suelo actual, como sería de esperar en el caso de que fueran actuales, sino que se distribuyen homogéneamente, como así lo confirma el test, con un nivel de significación de 0,50.

El resto de los cruces, Tipo frente a Raíces y Meteorización frente a Raíces, tampoco muestran que las variables estén relacionadas.

\section{COMPARACIÓN DE MEDIAS}

En las tres comparaciones realizadas, nivel 1 frente a nivel 2, nivel 1 frente a nivel 3 y nivel 2 frente a nivel 3 , los grados de significación son de $0,56,0,88$ y 0,47 . Es decir, si se rechaza la hipótesis nula (que no hay diferencias en las medias respectivas), la posibilidad de equivocarse sería del $56 \%, 88 \%$ y $47 \%$, con lo que puede concluirse que no hay diferencias significativas en cuanto a las medidas de los restos de unos niveles a otros.

\section{DIAGRAMAS EN ROSA DE LOS HUESOS ORIENTADOS}

Entre las dos cuadrículas se han medido un total de 98 restos orientados, que constituyen la tercera parte del total. Se midieron aquellos restos con una dirección predominante, y con una longitud suficiente para poder determinar su dirección sin equívocos. Los diagramas en rosa obtenidos, computando el total de piezas y realizados separándolas según los dos niveles de mayor concentración, indican una ligera predominancia de la dirección N-S en la cuadrícula B (Fig. 11). Tanto las medidas de paleocorrientes, como la litología de los clastos del sistema fluvial que divagaba y aportaba agua y sedimentos a la zona pantanosa, indican que éste tenía una dirección media E-O, con procedencia E. Por tanto, los huesos se orientaron mayoritariamente en sentido perpendicular a la dirección general de las paleocorrientes. Este comportamiento se ha observado en experimentos actuales cuando están bajo aguas someras que apenas los recubren (Voorhies, 1969). Estos aportes hídricos no trajeron elementos alóctonos al ámbito palustre mayores del tamaño arena media y aun éstos en pequeña cantidad. Sólo debieron tener la capacidad de reorientar un porcentaje de los restos óseos esparcidos en la superficie, pues el grueso de éstos muestran una orientación indeterminada. 


\begin{tabular}{||l|l|l|l|l||}
\hline CULLARBAZA & METEORIZACION 1 & METEORIZACION 2 & METEORIZACION 3 & TOTAL FILAS \\
\hline NIVEL 1 & 15 & 7 & 4 & 26 \\
& 16,0 & 7,4 & 4,3 & 27,7 \\
\hline NIVEL 2 & 12 & 3 & 3 & 18 \\
& 12,8 & 3,2 & 3,2 & 19,1 \\
\hline NIVEL 3 & 37 & 9 & 4 & 50 \\
& 39,4 & 9,6 & 4,3 & 53,2 \\
\hline TOTAL & 64 & 19 & 11 & 94 \\
COLUMNAS & 68,1 & 20,2 & 11,7 & 100 \\
\hline
\end{tabular}

\begin{tabular}{||l|l|l|l|l||}
\hline CULLARBAZA & METEORIZACION 1 & METEORIZACION 2 & METEORIZACION 3 & TOTAL FILAS \\
\hline NIVEL 1 & 15 & 7 & 4 & 26 \\
& 23,4 & 36,8 & 36,4 & 27,7 \\
\hline NIVEL 2 & 12 & 3 & 3 & 18 \\
& 18,8 & 15,8 & 27,3 & 19,1 \\
\hline NIVEL 3 & 37 & 9 & 4 & 50 \\
& 57,8 & 47,4 & 36,4 & 53,2 \\
\hline TOTAL & 64 & 19 & 11 & 94 \\
COLUMNAS & 68,1 & 20,2 & 11,7 & 100 \\
\hline
\end{tabular}

\begin{tabular}{||l|l|l|l|l||}
\hline CULLARBAZA & METEORIZACION 1 & METEORIZACION 2 & METEORIZACION 3 & TOTAL FILAS \\
\hline NIVEL 1 & 15 & 7 & 4 & 26 \\
& 57,7 & 26,9 & 15,4 & 27,7 \\
\hline NIVEL 2 & 12 & 3 & 3 & 18 \\
& 66,7 & 16,7 & 16,7 & 19,1 \\
\hline NIVEL 3 & 37 & 9 & 4 & 50 \\
& 74 & 18,0 & 8 & 53,2 \\
\hline TOTAL & 64 & 19 & 11 & 94 \\
COLUMNAS & 68,1 & 20,2 & 11,7 & 100 \\
\hline
\end{tabular}
$\chi^{2}$
2,75303
D.F.
4
Grado de significación
0,5999

Tabla 1. Tablas de contingencia del cruce entre las variables de meteorización (eje horizontal) y nivel (eje vertical). En el interior de las celdillas de la tabla superior, el programa indica los porcentajes totales, en las de la tabla del centro, los porcentajes por columnas, y en la tabla inferior, los porcentajes por filas. Los números superiores dentro de las celdillas corresponden al número de piezas óseas y los inferiores al porcentaje relativo. El valor del test $\chi^{2}=2,753$, los grados de libertad $=4$, y el grado de significación $=0,59$.

Contingence tables cross tabulation of category variables weathering (horizontal axis) and level (vertical axis). Inside the cells of the upper table total percentages are shown, the table in the centre shows percentages by columns, the table at the bottom shows percentages by rows. Inside each cell the numbers a top represent the totality of bones, the numbers at the bottom the relative percentages; Chi-square test $=2,753$; degrees of freedom $=4$, significance $=0,59$.

\section{PROCESO DE ACUMULACIÓN, AGENTES Y MECANISMOS}

\section{Actividad de depredadores-carroñeros}

La presencia de carroñeros-depredadores está testificada tanto por los restos fósiles encontrados en el yacimiento como por las señales de la actividad de éstos: coprolitos, restos óseos con marcas de dientes, bordes fracturados de forma aserrada producidos por mordiscos de depredadores, fracturas tipo "greenbone" que fueron realizadas por actividad de depredadores y/o carroñeros o por "trampling". El "trampling" es un proceso de pisoteo 


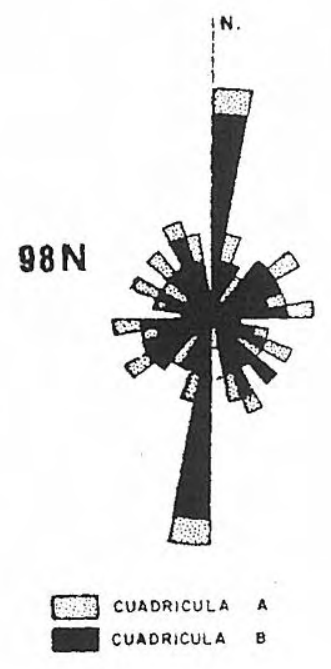

Figura 11. Diagrama en rosa de las orientaciones de los huesos largos de las cuadrículas A y B. Se destaca una orientación preferente N-S.

Rose diagram showing orientation of bones of grids $A$ and $B$, North-South direction is predominant.

de los huesos por otros animales que causa, muy frecuentemente, enterramiento y fracturación de los mismos (Shipman, 1981a; Behrensmeyer et al., 1986).

El porcentaje de costillas y vértebras es muy bajo (alrededor del 1,8\%) frente al de huesos largos (16\%), lo que indica también una participación importante de depredadores en la fracturación del conjunto, ya que en acumulaciones hechas por éstos hay un gran porcentaje de huesos largos, como metápodos, mientras que costillas y vértebras están poco representados. Ante la acción de depredadores y carroñeros un hueso tiene más probabilidades de sobrevivir cuanto mayor es su densidad (Shipman, 1981a).

\section{Muerte natural}

La acumulación de restos de mamíferos y de vertebrados en general, en las orillas y proximidades de medios palustres, ha sido ampliamente documentada (Shipman, 1981a; Brain, 1981; Andrews, 1990). Este hecho es debido a las características de este medio sedimentario que son especialmente atractivas para la fauna en general, que se concentra en sus proximidades para satisfacer necesidades vitales. En el yacimiento de Cúllar de Baza-1 se confirman estas observaciones, puesto que los niveles sedimentados durante encharcamiento palustre han librado mayor cantidad de restos óseos; así como fueron más accesibles a la fauna y pudieron actuar como trampas.

\section{Acción antrópica}

La presencia humana en la zona, esporádica o no, parece indiscutible ante la industria de lascas de sílex encontrada y los nueve grandes clastos de mármoles de una media de $25 \mathrm{~cm}$ de longitud y forma redondeada, que aparecen en la cuadrícula $\mathrm{B}$, a los que hay que añadir los encontrados en la excavación de 1976, que fueron ya interpretados como útiles transportados al área (Ruiz Bustos, 1984). A estos elementos aparecidos en la excavación debe asignárseles también un origen antrópico, siendo transportados como útiles hasta la zona del yacimiento ya que en ésta no existen materias primas que permitan su fabricación. Sin embargo, en el estado actual de conocimientos, no es posible determinar si hubo o no participación humana en la fracturación del conjunto. Actualmente no se considera que existan criterios inequívocos (Shipman, 1981b; Binford, 1981) para la identificación de la actividad antrópica sobre restos óseos a partir únicamente del estudio de la fracturación de éstos. En cuanto a su identificación a partir de "cut marks", tampoco hay un consenso al ser muy difícil, según el criterio de algunos autores, diferenciar las estrías producidas por otros procesos, como los de tipo "trampling" (Behrensmeyer et al., 1986). En cualquier caso, no se han observado estrías o marcas que pudieran asemejarse en principio a "cut marks".

\section{Modificaciones producidas por agentes atmosféricos}

Únicamente el $12 \%$ de los restos tienen un estado de meteorización avanzado y el $68 \%$ prácticamente no tienen indicios de meteorización. Esto indica que, aunque el enterramiento no fue instantáneo, los restos permanecieron en general poco tiempo expuestos a los agentes atmosféricos. Observaciones actuales señalan que un resto óseo expuesto a la intemperie queda en un estado de meteorización avanzado, especialmente en climas cálidos y secos, en un breve periodo de tiempo; 5 ó 10 años bastan para que quede totalmente deteriorado y separado en fragmentos (Shipman, 1981a). Por lo cual, para la mayoría de los restos se puede inferir un tiempo de exposición menor a estas cifras, que es congruente con el ambiente sedimentario del yacimiento.

\section{Modificaciones producidas por raíces}

Una cuarta parte de los restos muestran marcas milimétricas de un entramado de pequeñas raíces que han contribuido a deteriorar la superficie; éstas no son producto de la actividad de raíces actuales; por tanto, se produjeron penecontemporáneamente al depósito y durante la fase de enterramiento en la que los restos óseos estaban próximos a la superficie.

\section{Transporte-Selección fluvial}

No hay evidencias de aporte de restos óseos por corrientes superficiales. No se han encontrado restos resedimentados ni con señales de impactos. Por otra parte, la existencia de piezas en conexión anatómica es otro indicio de la escasa o nula selección que sufrieron. También hay criterios sedimentológicos que apoyan esta conclusión, ya que los elementos alóctonos aportados por las corrientes superficiales tenían únicamente tamaño arena media-fina, estando ausentes clastos de tamaño canto o bloque de varios centímetros, que corresponderían al equivalente hidráulico de los cráneos encontrados en estos niveles. Sin embargo, de forma ocasional, estas corrientes produjeron orientaciones de 
huesos como ya se ha señalado anteriormente. La ausencia de una concentración preferencial de dientes, y la abundancia de mandíbulas frente a dientes sueltos, es otro dato que tiende a descartar una influencia fluvial en la acumulación.

\section{CONCLUSIONES}

Este yacimiento se puede considerar como un conjunto de restos que se acumularon prácticamente in situ, en una zona encharcada muy somera, situada en las orillas de un sistema lacustre con sedimentación carbonatada. La zona estuvo sometida al menos a cuatro importantes oscilaciones en el espesor de la lámina de agua, que provocaron el cambio alternante de ambiente sedimentario palustre a otro lacustre, con una sedimentación de limos palustres (épocas de aguas bajas) a otra de carbonatos (épocas de aguas altas). Los niveles fosilíferos se formaron en las etapas con sedimentación palustre, que han dado lugar a dos concentraciones importantes y una tercera de menor entidad.

Los principales agentes responsables de la acumulación y fracturación total (reducción de los huesos a esquirlas previamente al enterramiento) o parcial (fracturas en fresco de piezas anatómicas reconocibles) de los restos fueron agentes biológicos. Esto se debió a la actividad de depredadores-carroñeros, o al pisoteo sobre los restos esparcidos en los alrededores del área palustre, o bien a acumulaciones de cadáveres por muerte natural. No se ha podido valorar la posible contribución de la acción antrópica en la formación del yacimiento. Los restos óseos no fueron concentrados ni transportados por corrientes aluviales o fluviales. El enterramiento fue rápido con una mayoría de restos escasamente meteorizados.

\section{AGRADECIMIENTOS}

A los Drs. Antonio Ruiz Bustos y Juan Antonio Peña, pioneros en la investigación paleontológica y geológica de la zona, por la información y apoyo recibido. A todos los miembros del equipo de excavación que trabajaron en la recuperación de los restos fósiles. A D. José Arroyo por la cuidadosa delineación de las figuras. Este trabajo se enmarca en los proyectos PB88-0008, PB91-0082, PB94-0071 y PB98-1250.

\section{BIBLIOGRAFÍA}

Alberdi, M.T., Alonso Diago, M.Á., Cerdeño, E. y Ruiz Bustos, A. 1989a. Investigaciones paleontológicas realizadas en la Cuenca de Guadix-Baza, entre 1983 y 1987. Trabajos sobre el Neógeno-Cuaternario, 11, 1552.

Alberdi, M.T., Alcalá, L., Azanza, B., Cerdeño, E., Mazo, A., Morales, J. y Sesé C. 1989b. Consideraciones bioestratigráficas sobre la fauna de vertebrados fósiles de la cuenca de Guadix-Baza (Granada, España). Trabajos sobre el Neógeno-Cuaternario, 11, 347-352.

Alberdi, M.T., Alonso, M.A., Azanza, B., Hoyos, M. and Morales, J. 2001. Vertebrate taphonomy in circum-lake environments: three cases in the Guadix Baza Basin (Granada, Spain). Palaeogeography, Palaeoclimatology, Palaeoecology, 165, 1-26.

Alonso Diago, M.Á. 1991. El Plio-Pleistoceno de la Cuenca de Guadix-Baza (zona occidental y área de Cúllar de Baza-1): estratigrafía, sedimentología y evolución paleogeográfica, tafonomía de yacimientos de vertebrados. Tesis doctoral, Universidad de Salamanca, $561 \mathrm{pp}$. (inédita).

Andrews, P. 1990. Owls, Caves and Fossils. British Museum (Natural History), London, 240 pp.

Barbadillo, L. 1989. Los Reptilia (Sauria y Amphisbaena) de los yacimientos Plio-Pleistocenos de la Cuenca de Guadix-Baza (sudeste español). Trabajos sobre Neógeno - Cuaternario, 11, 151- 166.

Behrensmeyer, A.K. 1978. Taphonomic and ecologic information from bone weathering. Paleobiology, 4, 150-162.

Behrensmeyer, A.K., Gordon, K.D. and Yanagi, G.T. 1986. Trampling as a cause of bone surface damage and seudocutmarks. Nature, 319, 768-771.

Bindford, L. 1981. Bones:ancient men and modern myths. Academic press, N.Y., 312 pp.

Bishop, W. 1980. Paleogeomorphology and continental Taphonomy. In: Fossils in the making (Eds. A.K. Behrensmeyer and A.P. Hill). University of Chicago Press, 20-40.

Brain, C.K. 1981. The Hunters or the Hunted. An Introducction to African Cave Taphonomy. The University of Chicago Press, $361 \mathrm{pp}$.

Civis, J. 1989. Microfauna (Foraminíferos y Ostrácodos) en el Neógeno y Cuaternario de la cuenca de Guadix-Baza y corredor de Huércal-Overa. Trabajos sobre el NeógenoCuaternario, 11, 119-126.

Cody, R.D. 1979. Lenticular gypsum: occurrence in nature and experimental determinations of effects of soluble green plant material on its formation. Journal of Sedimentology and Petrology, 49, 1015-1028.

Doadrio, I. y Casado, P. 1989. Nota sobre la ictiofauna continental de los yacimientos de la cuenca de GuadixBaza (Granada). Trabajos sobre el NeógenoCuaternario, 11, 139-150.

Hill, A.P. 1980. Early Postmorten Damage to the Remains of some Contemporary East African Mammals. In: Fossils in the Making (Eds. A.K. Behrensmeyer and A.P. Hill). The University of Chicago Press, 131-152.

Jiménez Fuentes, E. y Martín de Jesús, S. 1989. Quelonios fósiles de la cuenca de Guadix-Baza (Granada). Trabajos sobre Neógeno-Cuaternario, 11, 167-174.

Robles, F. 1989. Moluscos continentales del PlioPleistoceno de la cuenca de Guadix-Baza. Trabajos sobre Neógeno-Cuaternario, 11, 127-138.

Ruiz Bustos, A. 1976. Estudio sistemático y ecológico sobre la fauna del Pleistoceno Medio de las Depresiones Granadinas. El yacimiento de Cúllar de Baza-1. Tesis doctoral, Universidad de Granada, 293 pp. (inédito). 
Ruiz Bustos, A. 1984. El yacimiento paleontológico de Cúllar de Baza I. Investigación y Ciencia, 91, 20-28.

Shipman, P. 1981a. Life History of a Fossil. Harvard University Press, $221 \mathrm{pp}$.

Shipman, P. 1981b. Applications of scanning electron microscopy to taphonomic problems. Annales of the New York Academy of Sciences, 376, 357-386.

Vega Toscano, G. 1989. Ocupaciones humanas en el Pleistoceno de la Depresión de Guadix-Baza: elementos de discusión. Trabajos sobre Neógeno-Cuaternario, 11, 327-345.

Voorhies, M.R. 1969. Taphonomy and population dynamics of the early Pliocene vertebrate fauna, Knox County, Nebraska. Contributions of the Geological Society, Special Papers, 1, 1-69.

Wenninger, J.M. and Mc Andrews, J.H. 1989. Late Holocene aggradation in the Lower Humber River Valley, Toronto, Ontario. Canadian Journal of Earth Sciences 26, 1842-49.

Manuscrito recibido: 1 de marzo, 1996 Manuscrito aceptado: 12 de junio, 2001 